represent an application of Koch's postulates to the micro-ecology of the fungal flora of root surfaces. Charles G. C. Chesters M. W. Assawah

Department of Botany,

The University,

Nottingham.

Sept. 10.

${ }^{1}$ Harley, J. L., and Waid, J. S., Trans. Brit. Myool. Soc., 38, 104 (1955).

\section{Root Exudates of Paddy}

The importance of studying root exudates in understanding the behaviour of the rhizosphere microflora is now well recognized. Many techniques have been evolved for collecting root exudates under nonsterile conditions without regard to the attendant injury to root system and with the consequent sloughing off of the root cortex ${ }^{1}$. This communication records an attempt to overcome these defects in technique by collecting the exudates under sterile conditions, during the first week of the growth of the plants.

Two strains of paddy, one resistant (GEB.24) and the other susceptible (MTU.9) to the 'foot-rot' disease caused by Fusarium moniliforme were used as test plants. Two superimposed filter papers (Whatman No. 1) of approximately $8 \mathrm{~cm}$. diameter were placed in 'Pyrex' flasks, moistened with $1 / 10 \mathrm{~N}$ Richard's solution without sucrose (prepared from 'Analar' salts and 'Pyrex' glass-distilled water) and sterilized at $15 \mathrm{lb}$. pressure for $15 \mathrm{~min}$. Fifty seeds, surface sterilized and washed with several changes of glass-distilled water, were germinated under sterile conditions and transferred aseptically to each flask. After five days growth at room temperature (30$32^{\circ} \mathrm{C}$.), the plants were carefully removed without leaving any rootlets on the filter papers. The possibility of bacterial or fungal contamination of the test plants was checked at every stage by plating and microscopic examination. The filter papers were finely ground with 80 per cent alcohol, the extract centrifuged and the supernatant concentrated for analysis.

The technique of ascending chromatography of Williams and Kirby ${ }^{2}$ as modified by Lakshminarayanan $^{2}$ for unidimensional chromatograms was used to study the constituents of the exudates positive to ninhydrin employing $n$-butanol/acetic acid/water $(4: 1: 5)$ as the solvent mixture. As anticipated, several free amino-acids were present in the root exudates of both the resistant and susceptible strains. Their relative concentrations in each exudate were determined by visual observation of the intensity of the spots developing on the chromatogram (Table 1).

Table 1

\begin{tabular}{|c|l|c|c|}
\hline Material & Amino-acids & $\begin{array}{c}\text { Relative } \\
\text { concentration }\end{array}$ & $R F \cdot$ values \\
\hline \multirow{5}{*}{ Resistant } & Cystine & +++ & $0 \cdot 033$ \\
& Asparagine & ++++ & 0.073 \\
& Aspartic acid & ++ & 0.140 \\
& Glutamic acid & + & 0.176 \\
& Tyrosine & + & 0.320 \\
& Methionine & + & $0 \cdot 376$ \\
& Tryptophan & + & 0.446 \\
& Lysine & + & 0.602 \\
\hline \multirow{5}{*}{ Susceptible } & Aspartic acid & + & 0.140 \\
& Glutamic acid & + & 0.170 \\
& Tryptophan & + & 0.440 \\
& Lysine & + & 0.602 \\
\hline
\end{tabular}

The extracts from the control flasks where no plants were grown gave negative reactions to ninhydrin.

The results indicate that the four amino-acids found in the root exudates of the susceptible strain, namely, aspartic acid, glutamic acid, tryptophan and lysine, were also present in the root exudate of the resistant strain, almost in the same concentrations. However, the latter had four other amino-acids as well, namely, cystine, asparagine, tyrosine and methionine. Of these, cystine and asparagine were exuded in high concentrations. This result is significant, especially in view of an earlier report from this laboratory on the presence of cystine in strains of cotton resistant to Fusarium vasinfectum wilt". Such differences in the composition of root exudates of resistant and susceptible varieties have no doubt great influence on their specific rhizosphere microflora, and indeed further work in this direction appears to be a promising field of inquiry into the mechanism of resistance to root diseases in general.

We are indebted to Prof. T. S. Sadasivan and Dr. C. V. Subramanian for helpful suggestions.

\section{R. ANDal \\ K. Bhuvanthwari \\ N. S. SUBBA-RAO}

University Botany Laboratory,

Madras 5.

July 31.

${ }^{2}$ Katznelson, H., Rouatt, J. W., and Payne, T. M. B., Nature, 174, 1110 (1954). 'Parkinson, D., N ature, 176, 35 (1955). Bhuvaneswari, K., and Sulochana, C. B., Curr. Sci., 24, 376 (1955). Rovira, A.'D., Plant and Soil, 7,178 (1956).

2 Williams, R. J., and Kirby, H., Science, 107, 481 (1948).

${ }^{8}$ Lakshminarayanan, K., doctoral thesis, University of Madras (1956). - Lakshminarayanan, K., Proc. Ind. Acad. Sci., B, 41, 132 (1955).

\section{The Heterotrichous Habit in the Protonema of the Bryales}

DURING recent investigations on the development in aseptic culture of a range of typical representatives of the Bryales (species of twelve genera, from six orders) we have found that the protonema possesses a more definite morphological pattern than would appear to have been appreciated previously. Exam. ination of the advancing edge of isolated cultures growing on a solid substratum (Knop's agar or filter paper moistened with Knop's solution) has shown that in all the species studied, with the one exception of the aquatic moss Cinclidotus fontinaloides (Hedw.) P. Beauv., there is a striking distinction between a horizontal system of filaments ereeping in or on the substratum and an aerial system of filaments arising vertically or obliquely from the horizontal system. This "heterotrichous habit", to use a term employed by Fritseh ${ }^{1}$ for the corresponding condition in the algae, is well seen in Funaria hygrometrica Hedw. (Fig. 1), in which the prostrate system of a welldeveloped protonema is formed by stout brownwalled filaments with oblique septa and few chloroplasts, while the filaments of the aerial system, on the contrary, have hyaline walls, straight septa and numerous chloroplasts.

The relative degree of development of erect and prostrate systems, although influenced to some extent by environmental conditions, shows characteristic differences in the individual species, and some of the cultures are readily distinguished by their external 